\title{
E-learning in ophthalmology among undergraduate medical students in India during the COVID-19 pandemic
}

\author{
Ksheeraja Y, Soumya Ramani, Ananth Bhandary, Divya D. Sundaresh \\ MS Ramaiah Medical College and Hospitals, MSR Nagar, Mathikere, Bangalore, Karnataka, India
}

\begin{abstract}
BACKGROUND: The purpose of the study was to assess electronic learning (E-learning) effectiveness in understanding theoretical and clinical concepts in ophthalmology among undergraduate medical students during the COVID-19 pandemic.

MATERIAL AND METHODS: Third-year medical students in the ophthalmology term were enrolled after obtaining informed consent. Online classes were conducted from April 2020 after the commencement of lockdown. An online survey in the form of a questionnaire was issued to the students to evaluate the effectiveness of E-learning - 136 students participated in the survey. Students' perception of access to information technology (IT), internet connectivity, feedback on online learning of clinical skills, and theoretical concepts were evaluated. Students answered the questionnaire based on the Likert scale. The effectiveness of online teaching was assessed by student's performance in the online examination.

RESULTS: The percentage of students who had access to a computer was $72.2 \%$. Regarding understanding theory, $54.8 \%$ of students felt E-learning was effective, while $25.25 \%$ thought it was beneficial for clinics. The use of PowerPoint was considered valuable among $47.5 \%$ of students, and videos and images were helpful to understand concepts better. The barriers to E-learning were: lack of face-to-face interaction with teachers, peers (57\%), connectivity $(53.3 \%)$, and hardware and software issues $(45.2 \%)$. The $50.8 \%$ of students assessed online teaching as a method comparable to traditional teaching.

CONCLUSION: E-learning was found to be an effective alternative mode of learning concepts in ophthalmology. In the current setting of the COVID-19 pandemic, with the need to maintain social distancing, this mode of learning is very useful.
\end{abstract}

KEY WORDS: E-learning; COVID-19; assessment; online teaching

Ophthalmol J 2021; Vol. 6, 137-142

\section{INTRODUCTION}

E-learning - learning facilitated and supported through the application of technology - is pres- ently being used widely in all fields of education and being utilized extensively in medical education. E-learning has been a medium of instruction in 
many areas of education, including medical education, for many years. However, E-learning in medical education is still in its infancy [1].

E-learning involves technology and simulation, innovations that have brought a revolution in learning. Medical education also needs to imbibe this form of learning [2].

The United Nations (UN) and World Health Organisation(WHO) have acknowledged E-learning as a valuable tool in addressing educational needs in healthcare workers, especially in developing countries [3].

Medical education has many long-established pedagogical approaches to learning, including face-to-face lectures in classrooms - via a teacher-centered model.

Over the last few decades, there has been a shift in medical education practice from traditional forms of teaching to other media that employ online, distance, or electronic learning.

However, due to the sudden pandemic of COVID-19, the whole world came to a standstill due to the strict lockdown rules implemented by the government and the suspension of regular classes - theory and clinical for undergraduate students.

Hence E-learning by online classes helped the students to listen to their teachers and have regular classes online without disturbing their syllabus and timetable for the academic year.

The model is a suitable alternative as keeping colleges open poses a safety risk for students [4].

However, the transition from traditional to online learning is not without challenges.

This study aims to introduce the concept of E-learning and discuss its need and scope in medical education during the COVID-19 pandemic to maintain social distancing and at the same time to avoid disruption of the regular schedule of teaching for the academic year among undergraduate medical students.

\section{MATERIAL AND METHODS}

A prospective cross-sectional observational study was conducted between April 2020 and October 2020 at a medical college in south India. The study followed the tenets of the Declaration of Helsinki. All undergraduate course students in the ophthalmology term were included in the study after obtaining consent from the students.

Undergraduate students in the Ophthalmology term had online teaching from 1st April 2020, after the commencement of lockdown due to the COVID-19 pandemic. According to their regular schedule, online theory classes consisted of training the students in various topics in ophthalmology by teachers using PowerPoint presentations and various audio-visual aids to help students understand concepts via the Microsoft Teams application.

Clinical classes comprised of training the students in history taking, physical examination, and basic clinical procedures with the help of synchronous mode of online learning. Students had the access to online clinical skills videos, descriptive text with images, patient cases, and moderated discussion forums.

A total of 136 undergraduate students at the medical school participated in the survey. Consent was obtained from all the students. The survey focused on five major areas:

1. Perceived level of IT usage, accessibility, availability, connectivity.

2. Attitudes towards E-learning-understanding complex topics in the theory and clinical skills.

3. Usefulness of different media in E-learning.

4. Online assessment results.

5. Barriers to the development and implementation of effective online learning.

A questionnaire was sent to all 150 students, and the response was obtained.

The content validity of the questionnaire was evaluated by Ophthalmology experts, software specialists, and members of the Medical Education Unit.

The questionnaire was also evaluated through a pilot study carried out for ten students. A Cronbach alpha value was estimated to find out the reliability of the questionnaire (0.8).

The effectiveness of online teaching was also assessed by students' responses to the questionnaire and their performance in the online assessment conducted at the end of the term. The assessment included a theory question paper and multiple-choice questions, and clinical case scenarios.

All the categorical variables were represented as percentages. Numerical variables such as age and questionnaire total score(Likert's scale) were expressed in descriptive statistics such as mean and percentages. The analysis was carried out according to different components and associations and was tested for statistical significance by chi-square. All the data were analysed by SPSS software version 20 . 


\section{RESULTS}

Among the 150 questionnaires sent, 136 responses were obtained, with a response rate of $90.67 \%$. The average age of the respondents was 20 years. The respondents were those studying in the 3rd year of the undergraduate medical course.

\section{Access to IT and internet connectivity}

A large percentage of students had access to a computer $(72.7 \%)$, but a significant rate $(54 \%)$ preferred using a smartphone for online learning activities. Many students either agreed or strongly agreed to have confidence in the use of the Microsoft Teams application for online learning(61.9\%), as shown in Table 1.

\section{Experiences and feedback on online learning of clinical skills}

Students' responses to learning clinical skills via online teaching methods have been summarised in Table 2 and Figure 1. When asked about learning the concepts of history taking and confidence in taking a history, $32.5 \%$ disagreed or strongly disagreed, while $26.5 \%$ agreed or strongly agreed. However, when asked about more complex clinical

\begin{tabular}{|l|c|}
\hline \multicolumn{2}{|l|}{ Table 1. Access to IT and internet connectivity } \\
\hline Computer access [YES] & $\mathbf{7 2 . 7 \%}$ \\
\hline Type of computer \\
\hline Desktop & $3.6 \%$ \\
\hline Laptop & $39.6 \%$ \\
\hline Mobile & $54 \%$ \\
\hline Type of internet \\
\hline Wifi- & \\
\hline Modem & $46 \%$ \\
\hline Mobile hotspot & $4.3 \%$ \\
\hline
\end{tabular}

skills learning, students felt that their understanding of the concept and hence confidence in doing the task independently was inadequate.

\section{Experiences and feedback on online learning of theoretical concepts}

Across the various topics, it was found that most students(54.8\%) agreed or strongly agreed to understand the concepts taught through the online mode of teaching.

\section{Student's perception of various modes of conduct of online classes for theory and clinics}

Most students agreed or strongly agreed that the use of a PowerPoint presentation helped them understand concepts in theory $(47.5 \%)$. In contrast, most students disagreed or strongly disagreed that PowerPoint presentations (ppt) helped them understand the clinical aspects of ophthalmology (48.9\%).

But, pictures and videos were perceived as helpful in learning the clinical aspects $(54.8 \%)$ and the-

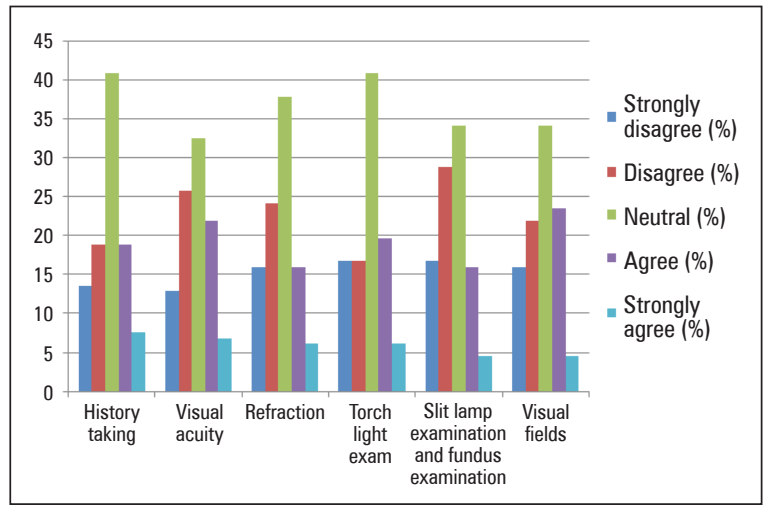

FIGURE 1. Experiences and feedback on online learning of clinical skills

Table 2. Experiences and feedback on online learning of clinical skills

\begin{tabular}{|l|c|c|c|c|c|} 
& $\begin{array}{c}\text { Strongly disagree } \\
(\%)\end{array}$ & Disagree (\%) & Neutral (\%) & Agree (\%) & Strongly agree (\%) \\
\hline History taking & 13.6 & 18.9 & 40.9 & 18.9 & 7.6 \\
\hline Visual acuity & 12.9 & 25.8 & 32.6 & 22 & 6.8 \\
\hline Refraction & 15.9 & 24.2 & 37.9 & 15.9 & 6.1 \\
\hline Torchlight exam & 16.7 & 16.7 & 40.9 & 19.7 & 6.1 \\
\hline $\begin{array}{l}\text { Slit-lamp examination } \\
\text { and fundus examination }\end{array}$ & 16.7 & 28.8 & 34.1 & 15.9 & 4.5 \\
\hline Visual fields & 15.9 & 22 & 34.1 & 23.5 & 4.5 \\
\hline
\end{tabular}




\begin{tabular}{|c|c|c|c|c|c|}
\hline & $\begin{array}{c}\text { Strongly } \\
\text { disagree } \%\end{array}$ & Disagree $(\%)$ & Neutral (\%) & Agree (\%) & Strongly agree (\%) \\
\hline Adequacy of duration of class & 11.2 & 10.4 & 29.1 & 31.3 & 17.9 \\
\hline $\begin{array}{l}\text { The usefulness of PPT in } \\
\text { theory }\end{array}$ & 9.6 & 11.1 & 31.9 & 31.9 & 15.6 \\
\hline $\begin{array}{l}\text { The usefulness of PPT in } \\
\text { clinics }\end{array}$ & 23.7 & 25.2 & 23 & 17.8 & 10.4 \\
\hline $\begin{array}{l}\text { The usefulness of images } \\
\text { and videos theory }\end{array}$ & 5.9 & 10.4 & 23 & 36.3 & 24.4 \\
\hline $\begin{array}{l}\text { The usefulness of images } \\
\text { and videos clinics }\end{array}$ & 11.9 & 11.1 & 22.2 & 33.3 & 21.5 \\
\hline Seminars & 23.7 & 20.7 & 31.1 & 20 & 4.4 \\
\hline $\begin{array}{l}\text { Opportunity to discuss with } \\
\text { teachers }\end{array}$ & 8.2 & 13.4 & 25.4 & 32.1 & 20.9 \\
\hline $\begin{array}{l}\text { The ability of teachers to keep } \\
\text { a check on online learning }\end{array}$ & 8.2 & 9.7 & 23.1 & 38.8 & 20.2 \\
\hline
\end{tabular}

PPT — Power Point

\begin{tabular}{|l|c|c|c|c|c|}
\hline & $\begin{array}{c}\text { Strongly disagree } \\
\text { T\%) }\end{array}$ & Disagree (\%) & Neutral (\%) & Agree (\%) & Strongly agree(\%) \\
\hline $\begin{array}{l}\text { The usefulness of MCQ } \\
\text { at the end of class }\end{array}$ & 5.9 & 8.9 & 24.4 & 36.3 & 24.4 \\
\hline Method of online assessment & 15.8 & 9.8 & 22.6 & 30.8 & 21.1 \\
\hline Theory results & 9.1 & 9.8 & 25.8 & 31.8 & 23.5 \\
\hline MCQ results & 9.8 & 4.5 & 22 & 37.1 & 26.5 \\
\hline $\begin{array}{l}\text { Online assessment correlation } \\
\text { with E-learning }\end{array}$ & 13.7 & 10.7 & 38.9 & 26.7 & 9.9 \\
\hline The results were better online & 13.1 & 16.9 & 36.2 & 21.5 & 12.3 \\
\hline
\end{tabular}

MCO - multiple choice questions

oretical aspects $(60.7 \%)$ of various ophthalmological diseases, as shown in Table 3.

\section{Students' perception of online assessment}

Students perceived that the multiple-choice questions at the end of the class were helpful (60.7\%). 36.6\% of students found that their online assessment results correlated with online learning (Tab. 4).

The average marks of students in the first internal assessment were $67.5 \%$ and in the second internal assessment was $62.8 \%$. On applying the unpaired t-test between the first and second internal assessment marks, the p-value was 0.0003 , which is statistically significant.

The first internal assessment was conducted in May, when the students had a combination of tra- ditional learning before the pandemic and online learning once the lockdown was imposed. The second assessment was completed in October, when the students had exclusive online learning. The results suggest that a blended learning approach is suitable for effective learning.

\section{Barriers to online learning}

Many students perceived the lack of face-to-face interaction with teachers (57\%) and lack of face-to-face interaction with peers $(57.4 \%)$ as a barrier to online learning. $53.3 \%$ of students faced connectivity issues, and $45.2 \%$ of students faced hardware and software issues during the online learning method. $50.8 \%$ of students opined that online teaching is comparable to the traditional classroom teaching method (Tab. 5). 


\begin{tabular}{|l|c|c|c|c|c|}
\hline \multicolumn{1}{|l|}{ Table 5. Barriers to online learning } & $\begin{array}{c}\text { Strongly disagree } \\
\text { (\%) }\end{array}$ & Disagree (\%) & Neutral (\%) & Agree (\%) & Strongly agree (\%) \\
\hline Hardware-software issues & 17.8 & 14.8 & 22.2 & 26.7 & 18.5 \\
\hline Connectivity issues & 11.1 & 20 & 15.6 & 25.2 & 28.1 \\
\hline $\begin{array}{l}\text { Lack of face-to-face interaction } \\
\text { with teachers }\end{array}$ & 6.7 & 14.9 & 22.4 & 19.4 & 36.6 \\
\hline $\begin{array}{l}\text { Lack of face-to-face interaction } \\
\text { with peers }\end{array}$ & 9 & 12.7 & 20.9 & 20.1 & 37.3 \\
\hline Anxiety due to COVID-19 & 13.4 & 14.2 & 23.1 & 26.9 & 22.4 \\
\hline $\begin{array}{l}\text { Online and traditional } \\
\text { comparable }\end{array}$ & 31.3 & 17.9 & 29.9 & 13.4 & 7.5 \\
\hline Distracting home environment & 18.7 & 18.7 & 16.4 & 26.1 & 20.1 \\
\hline Eyestrain & 7.5 & 15 & 21.8 & 16.5 & 39.1 \\
\hline
\end{tabular}

\section{DISCUSSION}

E-learning is a significant advance with the potential to change the face of medical education in India in the coming years. For this to happen, institutions and teachers must be prepared to accept the change and put in the required resources - whether manpower, time, or money.

When the WHO declared the COVID-19 caused by the 2019 novel coronavirus (Sars-CoV-2) as a pandemic on 11th March 2020, drastic changes have occurred in our lives. Social distancing and lockdowns have brought about a change in traditional learning. Resuming the conventional method of teaching may be delayed due to the ongoing pandemic. This has affected medical education, including learning in the ophthalmology field. Alternative educational and assessment strategies need to be initiated and effectively implemented [5].

It would be a good initiative for medical educators and administrators to incorporate these modalities in the current setting of the COVID-19 pandemic as there are strict measures of lockdown and the need to maintain social distancing. E-learning involves a pedagogical approach that should be flexible, interesting, and learner-centered, one that encourages interaction (staff-student, student-student), and collaboration, and communication. Elearning is the way forward, especially considering the raging COVID-19 pandemic. Also, it makes learning easy [1] and serves as an excellent adjunct to the traditional mode of learning [6].

Once the lockdown was announced in India, learning did not stop in our institute due to the advantage of online learning. This study was conducted to understand what the students perceived about the various aspects of online learning and assess whether the assessment scores reflected their perception. Social distancing being the norm, distant learning became the collateral. With this situation being unique in its occurrence and the fact that it has been sudden and unforeseen, immediate innovative methods of learning had to be moulded to match the needs of an Indian medical graduate [7].

In a study conducted by Desai et al., in comparison with classroom teaching, only $15 \%$ of respondents felt online classes were better, while $35 \%$ were neutral, and the rest disagreed. In our study, where the synchronous mode of learning was the primary mode, we found that $20.9 \%$ felt that the two ways of learning were comparable, while $29.9 \%$ were neutral. The rest disagreed about the comparability of the two modes of learning [8].

Vijayadas et al. concurred in their study that around $18 \%$ of the students felt that they did not get adequate time to interact with peers and faculty members. In our study, $56 \%$ of the students agreed that lack of face-to-face interaction with the teachers and peers was a significant barrier in the learning process. However, there was an opportunity to interact one-on-one and clarify the doubts in this synchronous form of learning [9].

There have been very few studies that have assessed online learning in undergraduate in the Ophthalmology field. This study asserts the students' opinion on the perceived merits and demerits of online learning. Student's perception was also compared with the scores obtained in the online assessment. In a study done by Gormley et al., where the blended approach was applied, $90.6 \%$ of the students felt that online learning was valuable to learn clinical skills.6 However, in our study, where only E-learning could be put into practice due to the 
COVID-19 situation, $61 \%$ felt that they were able to learn clinical skills with exclusive online teaching.

Undoubtedly, E-learning will become the future of ophthalmic education, used as a supplement to traditional teaching, with many virtual courses widely available to anyone with an internet connection and desire to learn worldwide. Embracing these changes will enable training programs to rise to the challenges of COVID-19 and ensure the provision of high-quality education for the future [10].

A collateral casualty of the COVID-19 pandemic is medical training, especially in non-emergency branches like ophthalmology which are not directly involved in COVID-19 patient care [11]. The post-pandemic era is likely to involve a hybrid model of virtual didactics and in-person clinical encounters. This new learning method provides students with novel opportunities in patient care and technical skill development while limiting unnecessary in-person interaction [12].

The limitation is the sample size; hence further studies could include undergraduate students across many medical colleges. Also, since different teachers handle each topic, there could be a bias.

E-learning was found to be an effective alternative mode of learning concepts in ophthalmology. In the current setting of the COVID-19 pandemic, with the need to maintain social distancing, this mode of learning is very useful. Though there are some caveats in this learning mode, it can still serve as a valuable addendum to traditional classroom learning.

Adapting to novel situations, such as the one imposed upon us by the novel coronavirus, is the need of the hour. Incorporation of the concept of online learning into the medical education curriculum is a valuable and pragmatic approach. Since IT technology is such a big part of our lives, innovative approaches represent a step forward in further improving medical education in ophthalmology during COVID-19 and beyond [13].

There are no conflicts of interest or funding sources.

\section{Conflicts of interest}

None declared.

\section{Funding}

None declared.

\section{REFERENCES}

1. Bandhu S, Raje S. Experiences with E-learning in Ophthalmology. Indian J Ophthalmol. 2014; 62(7): 792-794, doi: 10.4103/0301-4738.138297, indexed in Pubmed: 25116772.

2. Dhir $S$, Verma $D$, Batta $M$, et al. E-learning in medical education in India. Indian Pediatr. 2017; 54(10): 871-877, doi: 10.1007/s13312017-1152-9, indexed in Pubmed: 29120336.

3. Al-Shorbaji N, Atun R, Car J. E-learning for undergraduate health professional education - a systematic review informing a radical transformation of health workforce development. World Health Organization, Geneva 2015.

4. Dhotre S, Dhotre P, Shaikh A. Perspective of medical students on online teaching-learning process during COVID-19 pandemic. Indian J Health Sci Biomed Res (KLEU). 2020; 13(3): 197, doi: 10.4103/ kleuhsj.kleuhsj_235_20.

5. Kaup $S$, Jain $R$, Shivalli $S$, et al. Sustaining academics during COVID-19 pandemic: The role of online teaching-learning. Indian J Ophthalmol. 2020; 68(6): 1220-1221, doi: 10.4103/ijo.IJO 1241 20, indexed in Pubmed: 32461490.

6. Gormley GJ, Collins K, Boohan M, et al. Is there a place for elearning in clinical skills? A survey of undergraduate medical students' experiences and attitudes. Med Teach. 2009; 31(1): e6-12, doi: 10.1080/01421590802334317, indexed in Pubmed: 19253150.

7. Medical Council of India, published in PART III, Section 4, of the gazette of India dated 17th may 1997(Amended up to May 2018).

8. Desai D, Sen S, Desai S, et al. Assessment of online teaching as an adjunct to medical education in the backdrop of COVID-19 lockdown in a developing country - An online survey. Indian J Ophthalmol. 2020; 68(11): 2399-2403, doi: 10.4103/ijo.IJ0_2049_20, indexed in Pubmed: 33120627.

9. D V, M A. Impact of E-learning as a supplementary teaching learning tool in physiology. MedPulse Int J Physiol. 2017; 5(2): 08-12, doi: $10.26611 / 103521$.

10. Chatziralli I, Ventura CV, Touhami S, et al. International Retina Collaborative. Transforming ophthalmic education into virtual learning during COVID-19 pandemic: a global perspective. Eye (Lond). 2021; 35(5): 1459-1466, doi: 10.1038/s41433-020-1080-0, indexed in Pubmed: 32651545.

11. Mishra D, Nair AG, Gandhi RA, et al. The impact of COVID-19 related lockdown on ophthalmology training programs in India - Outcomes of a survey. Indian J Ophthalmol. 2020; 68(6): 999-1004, doi: 10.4103/ ijo.IJO 106720 , indexed in Pubmed: 32461413.

12. Duong ATT, Van Tassel SH, Alzaga Fernandez AG, et al. Medical Education and Path to Residency in Ophthalmology in the COVID-19 Era: Perspective from Medical Student Educators, Ophthalmology. 2020; 127(11): e95-e98, doi: 10.1016/j.ophtha.2020.07.036, indexed in Pubmed: 32712074.

13. Wendt $S$, Abdullah Z, Barrett $S$, et al. A virtual COVID-19 ophthalmology rotation. Surv Ophthalmol. 2021; 66(2): 354-361, doi: 10.1016/j. survophthal.2020.10.001, indexed in Pubmed: 33058927. 